\title{
PENANGANAN PELANGGARAN SERTA PERAN APARATUR SIPIL NEGARA (ASN) SEBAGAI PENCIPTA IKLIM KONDUSIF DEMOKRASI DALAM PENYELENGARAAN PEMILU
}

\author{
Suhendar, \\ Riva Rachmi Kusumah \\ Universitas Wiralodra \\ Email : suhendarabas_sap@yahoo.com, \\ rivarachmikusmah@gmail.com
}

\begin{abstract}
Neutrality is an important capital for the State Civil Apparatus (ASN) as the government organizer. However, it is not easy to realize the principle called neutrality. There are several factors that make it difficult for ASNs to be neutral. First, the massive amount of $A S N$. ASN has a good understanding of the government's governance policies, as well as the authority possessed by the country's civil apparatus. Various regulations related to elections both in the handling of violations and the state civil apparatus are indeed well structured, but they should be able to reduce the potential behavior of the community, election participants and election organizers, but the potential for violations in the general election yesterday was large enough so that the authors are interested in researching deeper, based on Indonesia being a state of law both the government and its people must obey and abide by existing laws, but unfortunate law made easily by the public is one of the regulations related to general elections, this paper focuses on the role of the state civil apparatus in organizing general elections and handling election violations in the Indramayu district
\end{abstract}

Keywords: Neutrality, General Elections, Election Violations.

\section{PENDAHULUAN}

Kerangka negara demokrasi dalam pelaksanaan Pemilihan Umum (Pemilu) merupakan momentum yang sangat penting bagi pembentukan pemerintahan dan penyelenggaraan negara periode berikutnya, sebagai negara yang menghelat pesta demokrasi dalam wujud pemungutan suara setiap lima tahun sekali, Indonesia terus bersolek mempercantik diri lebih baik lagi, baik dari segi sistem penyelenggaran pemilu, efektivitas kinerja penyelenggara pemilu, hingga kepada hal-hal yang menurut asumsi sebagian orang tidak terlalu penting, namun erat kaitannya dengan prinsip dasar pemilu yang sangat esensial, Persoalan mengenai Netralitas Aparatur Sipil Negara (ASN) dalam setiap penyelenggaraan Pemilu.

Sebagai pihak yang dekat dengan penguasa (eksekutif), Aparatur Sipil Negara kerap kali dipolitisasi dan dimobilisasi oleh pemangku kepentingan yang muara utamanya, ialah mendulang suara yang siginifikan dalam setiap kontestasi baik Pemilihan Umum Legislatif, Presiden, maupun Pemilihan Kepala Daerah (Pilkada). Hal tersebut tidak dapat 
dipungkiri menjadi bahaya laten yang jika ditengok ke belakang memiliki sejarah panjang dalam melanggengkan kekuasaan orde baru yang bercokol selama 32 tahun ${ }^{1}$.

Masih tingginya angka pelanggaran Netralitas Aparatur Sipil Negara (ASN) pada Pemilihan Umum Tahun 2019, yaitu sekitar 1.096 pelanggaran hukum terkait netralitas ASN, TNI dan Polri saat Pemilu 2019. Bahkan jika dirinci lebih jauh, Badan Kepegawaian Negara $(\mathrm{BKN})$ merilis bahwa dari data Pelanggaran terhadap Netralitas Aparatur Sipil Negara (ASN) Pada pemilu 2019 tersebut, sekitar 99,5\% diantaranya terjadi di Instansi Daerah seperti Pemerintah Provinsi sampai dengan Pemerintah Kabupaten/Kota. Hal tersebut, tentunya menjadi Pekerjaan Rumah bersama yang tidak dapat dikesampingkan begitu saja mengingat tugas Aparatur Sipil Negara (ASN) ialah memberikan pelayanan kepada masyarakat (public service) sebaik-baiknya tanpa tersangkut suatu kepentingan apapun $^{2}$.

Apabila jajaran Aparatur Sipil Negara (ASN) mengedepankan kepentingan calon yang didukungnya, apalagi ia merupakan seorang petahana (incumbent), maka hal tersebut menurut hemat penulis dapat menimbulkan setidaknya dua efek mengerikan, yaitu Pertama akan menghasilkan Sumber Daya Aparatur yang mengesampingkan kebutuhan masyarakat, Ketidaknetralan Aparatur Sipil Negara yang cenderung fokus terhadap kepentingan calon yang didukungnya akan mengesampingkan tugas pokok dan fungsinya sebagai pelayan publik.

Kedua, dengan terindikasinya Aparatur Sipil Negara yang tidak netral, dapat menimbulkan konflik kepentingan (conflict of interest) dan sentimen politik tingkat tinggi ketika berjalannya roda pemerintahan (birokrasi) berlangsung. Puncaknya, seorang yang dianggap tidak mau mendukung berpotensi mendapatkan stigma dislike dari yang bersangkutan yang pada akhirnya mendapatkan ancaman baik mulai dari pindah tugas (mutasi) sampai kepada intimidasi pemecatan.

Dalam penyelengaraan pemilu harus dapat dipastikan bahwa prinsip dan asas-asas pemilu telah dapat dilaksanakan secara baik dan benar, namun dalam setiap tahapan

\footnotetext{
${ }^{1}$ Jimly Asshiddiqie, Pengantar Ilmu Hukum Tata Negara.Jakarta: Rajawali Pers, 2019, hlm. 31.

${ }^{2}$ Data Daring Bawaslu RI https://www.bawaslu.go.id/id/berita/bawaslu-tangani-ribuan-pelanggaran-net ralitas-asn-saat-pemilu-2019) diakses pada tanggal 14 Februari 2020 Pukul 09:15 WIB.
} 
penyelengaraan pemilu, memungkinkan terjadinya pelanggaran baik oleh penyelenggara, peserta pemilu, maupun oleh pemilih ${ }^{3}$.

Pelanggaran dapat dilakukan banyak pihak bahkan dapat dikatakan semua orang memiliki potensi untuk melakukan pelanggaran. Pelanggaran Pemilu itu sendiri dapat didefinisikan sebagai perbuatan yang melanggar peraturan mengenai Pemilihan Umum yang dalam hirarki peraturan perundang-undangan yang tertinggi selain Undang-Undang Dasar 1945 adapun undang-undang yang mengatur khusus terkait Pemilihan Umum yaitu Undang-undang Nomor 7 Tahun 2017 tentang Pemilihan Umum. Dari uraian sebagaimana telah diuraikan diatas dalam penulisan ini penulis akan mengkaji lebih dalam terkait Netralitas peran ASN (Aparatur Sipil Negara) dan bagaimana mekanisme penanganan pelanggaran dalam penyelengaraan Pemilu serentak pada tahun 2019 di Kabupaten Indramayu.

Berdasarkan latar belakang permasalahan diatas maka penulis mengangkat permasalahan yang akan di teliti sebagai berikut:

1. Bagaimana Netralitas ASN dalam Penyelengaraan Pemilihan Umum serentak pada tahun 2019 di Kabupaten Indramayu?

2. Bagaimana Penanganan Pelanggaran Pemilu pada pemilu serentak di Kabupaten Indramayu?

\section{METODE}

Sifat penelitian dalam penulisan ini ialah deskriptif yang dilakukan dengan pendekatan yuridis normatif, jenis dan sumber data yang digunakan adalah data sekunder. Pengumpulan data dilakuakn terutama dengan teknik studi dokumen (library research and online research) dengan menginvestasikan data sekunder yang diperlukan, baik berupa bahan hukum primer, sekunder maupun tersier, kemudian melakukan penelusuran sejarahnya dan singkronisasi antar bahan hukum tersebut. Bahan hukum primer yang dipergunakan terdiri dari peraturan perundang-undangan terutama yang berkaitan dengan Pemilihan Umum. Bahan hukum sekunder yang akan digunakan antara lain berupa, karya ilmiah hasil penelitian dan literatur yang berkaitan dengan subtansi penelitian. Bahan hukum tersier yaitu bahan-bahan yang menunjang informasi bahan hukum primer dan sekunder, antara lain data dari jurnal, kamus hukum, maupun ensiklopedia.

\footnotetext{
${ }^{3}$ Sri Hartini, "Penegakan Hukum Netralitas Pegawai Negeri Sipil (PNS)", Jurnal Dinamika Hukum, Vol. 9. No. 3, September 2009, hlm. 9.
} 


\section{HASIL DAN PEMBAHASAN}

\subsection{Netralitas ASN dalam Penyelengaraan Pemilihan Umum serentak pada tahun 2019 di Kabupaten Indramayu}

Tolak ukur sebuah Pemilihan Umum yang Langsung, Umum, Bebas, Rahasia Jujur, dan Adil (Luberjurdil) menurut hemat penulis tentunya tidak dapat dilihat secara parsial hanya dengan menilai bahwa Komisi Pemilihan Umum (KPU) sukses menunaikan tugasnya dalam menyelenggarakan Pemilihan Umum, Badan Pengawas Pemilihan Umum (Bawaslu) yang sukses mengawasi seluruh tahapan, hingga Dewan Kehormatan Penyelenggara Pemilu (DKPP) yang sukses menjaga etika, moralitas, harga diri, dan marwah penyelenggara pemilu untuk mendapatkan kembali kepercayaan dari publik (public trust), melainkan di dalamnya harus terdapat peran Aparatur Sipil Negara (ASN) yang pro-aktif menjaga independensi dan netralitasnya agar tidak menjadI alat untuk mempermudah tercapainya tujuan politik ${ }^{4}$.

Pemilihan Umum Tahun 2019 kemarin meskipun berhasil dihelat dengan cukup baik, namun masih menyisakan sejumlah persoalan serius salah satunya ialah masih banyaknya Aparatur Sipil Negara (ASN) yang dimobilisasi, dipolitisasi, dan diintervensi demi menaikkan popularitas mereka yang berkepentingan. Kondusifitas setiap event pesta demokrasi lima tahunan bertajuk Pemilihan Umum tidak hanya dilihat melalui dimensi kuatnya sinergitas TNI-Polri, intensifnya peran Bawaslu dalam menangani Pelanggaran Pemilu, masifnya sosialisasi KPU kepada masyarakat untuk menekan angka golput, namun lebih dari itu iklim kondusif demokrasi kita harus tercipta dengan kuatnya kesadaran penguasa baik di pusat maupun daerah untuk menertibkan para Aparatur Sipil Negara (ASN) untuk bersikap netral sekalipun mereka merupakan masyarakat sipil yang memiliki hak pilih. Spirit Netralitas Aparatur Sipil Negara harus dibangun pertama kali melalui mereka yang memiliki kewenangan langsung terhadap jajaran Aparatur Sipil Negara agar kita menegasikan kata-kata dari Lord Acton, yakni Power tends to corrupt, and absolute power corrupts absolutely. Apabila dilihat dalam angka Pelangaran Pemilu Pada tahun 2019 di Kabupaten Indramayu terdapat 276 Pelanggaran dengan spesifikasi sebagai berikut 255 Temuan, 21 Laporan, 266 di Registrasi, 10 tidak diregistrasi terbagi kedalam ke beberapa jenis pelangaran, diantaranya 246 Pelanggaran Administrasi Pemilihan, 1 Pidana Pemilu, 7 Pelanggaran Kode Etik, 11 Bukan Pelanggaran dan 1 Pelanggaran Undang-

\footnotetext{
4 Marbun, S.F, Reformasi Hukum Tata Negara, Netralitas Pegawai Negeri dalam Kehidupan Politik di Indonesia. Yogyakarta: Fakultas Hukum Universitas Islam Indonesia, 1998, hlm.12.
} 
undang lainya, apabila dilihat dalam angka tersebut pelanggaran ASN sebagaima dimaksud dalam uraian di atas termasuk kedalam spesifikasi pelanggaran undang-undang lainya terdapat 1 kasus yang berkaitan dengan ASN di Kabuapaten Indramayu pada pemilu 2019 lalu yang dikeluarkan putusan secara resmi oleh KASN (Komisi Aparatur Sipil Negara) ${ }^{5}$.

\subsection{Penagganan Pelanggaran Pada Pemilu serentak di Kabupaten Indramayu}

Dalam Pelaksanaan Pemilihan Umum serentak tahun 2019 baik Pemilihan eksekutif Maupun Pemilihan Legislatif, Pelanggaran Pemilihan Umum (Pemilu) tidak hanya didefinisikan sebagai suatu Perbuatan yang melanggar undang-undang Nomor 7 Tahun 2017 saja, akan tetapi Pelanggaran Pemilihan Umum dapat diartikan suatu berbuatan yang dilakukan secara perseorangan atau bersama-sama ketika melanggar aturan yang berkaitan dengan aturan Pemilihan Umum, selanjutnya dalam pelanggaran Pemilihan Umum ini dapat diklasifikasikan menjadi tiga Pelanggaran yang terdiri dari, Pelanggaran Administratif Pemilu, Pelanggaran Pidana Pemilu, dan Pelanggaran Kode Etik ${ }^{6}$.

Dalam Pelasanaan Pemilihan Umum pada tahun 2019, berdasarkan data penanganan pelanggaran yang di tangani oleh Bawaslu Kabupaten Indramayu terdapat 276 Laporan/Temuan. Dalam Temuan dan Laporan Penanganan Pelanggaran Pemilu ini dapat diuraikan jumlah Penanganan Pelanggaran dalam pertahapan dalam Pemilihan Umum 2019.

Dimulai dari tahap Pencalonan, Tahap Pemutakhiran data Pemilih Terdapat 24 temuan yang terbagi menjadi 23 Pelanggaran Administrasi dan 1 Bukan Pelanggaran, Tahapan Pendaftaran dan Verifikasi Peserta, terdapat 1 Laporan dan masuk ke dalam bukan Pelanggaran, Tahapan Peserta Pemilu, Tahapan Penetapan Kursi dapil, Tahapan Pencalonan Presiden, dan Legislatif terdapat 1 Temuan dan masuk ke dalam Pelanggaran Administrasi, Tahapan Masa Tenang terdapat 4 Temuan dan 1 Laporan dan 1 tidak diregistrasi, 4 diregistrasi, yang masuk ke dalam pelanggaran 1 Administrasi, 2 Etik dan 1 Bukan Pelanggaran, selanjutnya di tahapan Kampanye terdapat 229 Temuan, 16 Laporan, 9 Tidak di Registrasi, 236 di registrasi, 218 Pelanggaran Administratif, 1 Pidana, 7 Etik, 9 Bukan Pelanggaran dan 1 Pelanggaran Undang-undang lainya, pada Tahapan Pungut Hitung terdapat 1 Temuan dan Masuk Pelanggaran Administrasi, dan ditahapan Penetapan

\footnotetext{
5 Bawaslu Kabupaten Indramayu "Dibalik Pintu Pengawasan” Bawaslu Kabupaten Indramayu, pada Pemilu serentak 2019, Indramayu. hlm. 55.

6 Kadarsih, Setiajeng, dan Sri Hartini, Makalah Netralitas Pegawai Negeri, Yogjakarta, 2005, hlm. 31.
} 
Hasil terdapat 4 Laporan 1 Tidak di registrasi dan 3 masuk kedalam Pelanggaran Administrasi.

Temuan pelanggaran pemilu menurut perbawaslu nomor 7 tahun 2018 adalah hasil pengawasan bawaslu, bawaslu provinsi, dan/atau bawaslu kabupaten/kota, panwaslu kecamatan, panwaslu kelurahan/desa, dan panwalu LN serta pengawas TPS pada setiap tahapan penyelenggaraan pemilu yang mengandung dugaan pelanggaran. Dalam tahun 2019, Bawaslu Kabupaten Indramayu telah memproses 276 kasus dugaan pelanggaran, dari jumlah tersebut sebanyak 255 kasus merupakan temuan Panwaslu Kecamatan dan Bawaslu Kabupaten. Dari temuan tersebut pelanggaran Administrasi sebanyak 246 kasus, pidana 1 kasus, kode etik 7 kasus dugaan pelanggaran.

Pelanggaran-pelanggaran tersebut terjadi di setiap tahapan pemilu, baik pada tahapan pemutahiran daftar pemilih, Pendaftaran dan Verifikasi Peserta, Penetapan Peserta, Penetapan Peserta Pemilu, Penetapan Kursi Dapil, Pencalonan Pileg dan Pilpres, Tahapan Kampanye, tahapan Pungut Hitung, Penetapan Hasil, dan Pengucapan Sumpah dan Janji yang akan diuraikan dalam tabel berikut:

Tabel 1.1

Temuan Dan Laporan Pelanggaran Pemilu Per Tahapan

\begin{tabular}{|c|c|c|c|c|c|c|c|c|c|}
\hline \multirow[b]{2}{*}{ no } & \multirow[b]{2}{*}{ Thepes Femile } & \multirow[b]{2}{*}{ Trmman } & \multirow[b]{2}{*}{ Lepores } & \multirow[b]{2}{*}{$\begin{array}{l}\text { That } \\
\text { Niecinter }\end{array}$} & \multicolumn{4}{|c|}{ 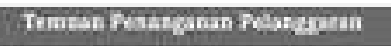 } & \multirow[b]{2}{*}{ Lalnny } \\
\hline & & & & & Wtin & Homs & rile & $\begin{array}{l}\text { Mowh } \\
\text { Massain }\end{array}$ & \\
\hline 1. & Fotncatasn & $=$ & 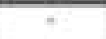 & $=$ & 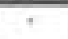 & r & * & + & + \\
\hline 2 & Wascalhinas Dif & 24 & + & - & 23 & - & + & $\mathrm{t}$ & $*$ \\
\hline 3. & Tendaflarah dan Verifkes Petcrta & + & 1 & 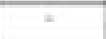 & 4 & * & " & $t$ & - \\
\hline 4. & Penetsesen Fesersa Fenils & + & * & 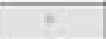 & 4 & ? & * & 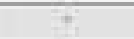 & " \\
\hline $\mathrm{s}$ & Wartapen Kura bapd & - & + & + & + & - & + & - & $*$ \\
\hline h & Penculenen Pigtes itan Firk & 1 & + & 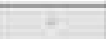 & 7 & 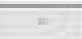 & 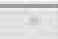 & $T$ & s. \\
\hline T. & Kampeniye & $2 \pi$ & 15 & * & 218 & 1 & 7 & 7 & 1 \\
\hline n. & Tima tenate & 2 & 1 & $i$ & 1 & $=$ & 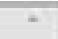 & 7 & * \\
\hline$a$ & Pungut Hoifg & $t$ & * & $\bar{*}$ & I & * & s & t & 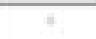 \\
\hline 10. & Fenelicen Hasil & - & 4 & $t$ & 3 & $=$ & $=$ & 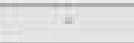 & 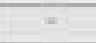 \\
\hline 11. & Rengucspan Sumpah Jenji & $=$ & $*$ & $*$ & $*$ & $=$ & $*$ & $*$ & $*$ \\
\hline & Jumlah total & 255 & 21 & 10 & 246 & 1 & 7 & 11 & 1 \\
\hline
\end{tabular}

\section{1) Pelanggaran Administratif Pemilu}

Objek Pelanggaran Administratif Pemilu, ialah berupa perbuatan atau tindakan yang melanggar tata cara, prosedur, atau mekanisme yang berkaitan dengan administrasi pelaksanaan Pemilu dalam setiap tahapan Penyelenggaraan Pemilu. Pelanggaran Admininistratif Pemilu sendiri dapat diartikan secara luas sebagai pelanggaran yang meliputi tata cara, prosedur, dan mekanisme yang berkaitan dengan administrasi 
pelaksanaan Pemilu dalam setiap penyelenggaraan Pemilu di luar tindak pidana pemilu dan penyelenggaraan kode etik Penyelenggara Pemilu.

Dalam Proses Penanganan Pelanggaran yang ditangani oleh Bawaslu Kabupaten Indramayu terdapat kurang lebih 246 Pelanggaran Administratif Pemilu, dari 246 pelanggaran pemilu 240 kasus merupakan temuan Panwaslu Kecamatan dan Bawaslu Kabupaten baik yang ditindaklanjuti maupun dihentikan melalui Pemberitahuan tentang Status temuan yang dituangkan kedalam Form B.15.

Selanjutnya, dari 246 temuan Pelanggaran Administratif yang ditangani oleh Panitia Pengawas Pemilihan Umum Kecamatan dan Bawaslu Kabupaten Indramayu apabila diuraikan melalui tahapan pemilihan umum pada tahun 2019 didominasi oleh 230 Pelanggaran Administratif Penertiban APK yang dilakukan oleh Satuan Polisi Pamong Praja Kabupaten Indramayu Bersama dengan Panitia Pengawas Pemilu Kecamatan, dan 16 pelanggaran Administratif Pemilu yang ditangani oleh Bawaslu Kabupaten Indramayu Tergolong kedalam Pelanggaran Administrasi Umum, baik diselesaikan melalui Sidang Acara Cepat maupun Sidang Adjudikasi Administratif Pemilu.

\section{2) Tindak Pidana Pemilu}

Pidana Pemilu dapat diartikan semua tindak pidana yang berkaitan dengan pemilu dan dilaksanakan pada tahap penyelenggaraan pemilu baik yang diatur dalam Undangundang Pemilu maupun dalam Undang-undang Tindak Pidana Pemilu dan penyelesaiannya di luar tahapan pemilu melalui Peradilan Umum. Bahwa pada Pelaksanaan Pemilihan Umum 2019 Bawaslu Kabupaten Indramayu melakukan Penyelesaian Pelanggaran Pemilu sampai dengan adanya Putusan Pengadilan yang Ingkrah, dengan Nomor Temuan 007/TM/PL/Kab/13.18/XII/2018, yang ditemukan oleh Panitia Pemilihan Umum Kecamatan Indramayu. Perkara Pidana Pemilu Ini tidak lepas dari kerjasama dari Anggota Gakkumdu Kabupaten Indramayu yang terdiri dari Unsur Penyidik, Kepolisian Kejaksaan maupun unsur Bawaslu yang dimana temuan tersebut dikaji dan dibahas dalam Rapat Sentra Gakkumdu I-IV, yang membahas tentang klarifikasi terkait saksi-saksi maupun Pelimpahan Temuan tersebut ke pihak Kepolisian, yang dilanjut di buka di Pesidangan Pemilhan Umum.

Uraian setiap pelanggaran pidana pemilu baik yang bersumber temuan dan laporan yang terjadi pada saat tahapan pemutahiran daftar pemilih, Pendaftaran dan Verifikasi Peserta Penetapan Peserta, Penentapan Peserta Pemilu, Penetapan Kursi Dapil, Pencalonan 
Pileg dan Pilpres, Tahapan Kampanye, tahapan Pungut Hitung, Penetapan Hasil, dan Pengucapan Sumpah dan Janji. Dalam Proses Penyelesaian Pelanggaran Pidana Pemilu terdapat 11 Dugaan Pelanggaran Pidana, pemilu yang terbagi kedalam Pembahasan Kajian Sentra Gakkmdu I sejumlah 9 Kasus, Pembahasan Sentra Gakkumdu I 1 Kasus, dan 1 Kasus yang ditetapkan sebagai Pelanggaran Pidana Pemilu menghasilkan putusan pengadilan yang Inkrah.

\section{3) Pelanggaran Lainya (Pelanggaran Undang-undang Lainya)}

Pelanggaran Undang-undang lainnya dapat didefinisikan berupa suatu Pelanggaran yang dilakukan oleh Peserta Pemilu maupun Penyelenggara Pemilihan umum namun subtansi Pelanggaran maupun sanksi tidak diatur dalam Undang-undang maupun regulasi yang berkaitan dengan Pemilihan Umum.

Dalam Penanganan Pelanggaran Pemilihan umum, khususnya di Kabupaten Bawaslu Kabupaten Indramayu menerima satu Temuan yang dilakukan oleh Aparatur Sipil Negara, selanjutnya Dugaan Pelanggaran Pemilu ini direkomendasikan Oleh Bawaslu Kabupaten Indramayu kepada Instatnsi yang berwenang menyelesaikan sengketa tersebut kepada Komisi Aparatur Sipil Negara (KASN) dengan nomor temuan 09/TM/PL/PPLSegeran Kidu1/JB-09.J.13/XI/2018, dalam Pelanggaran Lainya ini tetap di tindaklanjuti meskipun subtansi pelanggaran tidak ada di atur Undang-undang Nomor 7 tahun 2017 tentang Pemilihan Umum namun dilimpahkan ke Lembaga lain yang berwenang ${ }^{7}$.

\section{PENUTUP}

\subsection{Simpulan}

Dari uraian diatas dapatlah dikemukakan bahwa beberapa kesimpulan antara lain sebagaui berikut:

1. Pemilihan Umum Tahun 2019 kemarin meskipun berhasil dihelat dengan cukup baik, namun masih menyisakan sejumlah persoalan serius salah satunya ialah masih banyaknya Aparatur Sipil Negara (ASN) yang dimobilisasi, dipolitisasi, dan diintervensi demi menaikkan popularitas mereka yang berkepentingan. Kondusifitas setiap event pesta demokrasi lima tahunan bertajuk Pemilihan Umum tidak hanya dilihat melalui dimensi kuatnya sinergitas TNI-Polri, intensifnya peran Penyelengara Pemilu seperti Bawaslu yang memiliki kewenangan dalam

\footnotetext{
${ }^{7}$ Dibalik Pintu Pengawasan Bawaslu Kabupaten Indramayu, pada Pemilu serentak 2019, Indramayu, hlm. 62.
} 
menangani Pelanggaran Pemilu, masifnya sosialisasi KPU kepada masyarakat untuk menekan angka golput, namun lebih dari itu iklim kondusif demokrasi kita harus tercipta dengan kuatnya kesadaran penguasa baik di pusat maupun daerah untuk menertibkan para Aparatur Sipil Negara (ASN) untuk bersikap netral, oleh karenanya dalam pelaksanaan pemilihan umum masih ditemukan Aparatur Sipil Negara yang tidak netral dalam penyelengaraan pemilihan umum, khususnya di Kabupaten Indramayu.

2. Penegakan hukum adalah proses dilakukannya upaya untuk tegaknya atau berfungsinya norma-norma hukum secara nyata sebagai pedoman perilaku dalam lalu-lintas atau hubungan-hubungan hukum dalam kehidupan bermasyarakat dan bernegara. Jika melihat pada standar terakhir (kepatuhan dan penegakan hukum pemilu), adalah penting untuk memastikan pelaksanaan pemilu yang adil. Tingginya angka pelangaran pemilu yang ditangani oleh Badan Pengawas Pemilihan Umum Kabupaten Indramayu, dapat dijadikan tolak ukur bahwa kurangnya pemahaan masyarakat terkait larangan-larangan apa saja yang tidak boleh dilakukan pada saat terselengaranya penyelengaraan pemilu, mulai dari larangan pada tahapan-tahapan yang sudah di tetapkan mulai dari Pemutakhiran data pemilih sampai dengan Penetapan Hasil Pemilihan Umum.

\subsection{Saran}

Memperhatikan hasil simpulan di atas, dapat dikemukakan beberapa saran sebagai berikut :

1. Netralitas Pegawai Negeri Sipil merupakan suatu wacana nasional dalam era reformasi ini, dilihat dari peranan Pegawai Negeri Sipil yang begitu besar sehingga sangat di perlukan pembinaan yang baik. Dimana di harapkan Pegawai Negeri Sipil tidak lagi menjadi tunggangan politik yang dapat mempengaruhi sistem dalam bernegara. Adanya Undang-Undang Nomor 5 Tahun 2015 tentang aparatur sipil negara dapat di jadikan rel bagi Pegawai Negeri Sipil untuk melaksanakan tugas, kewajiban dan peranannya. Yang kedua adanya faktor-faktor yang dapat mempengaruhi kenetralitasan Pegawai Negeri Sipil tidak dapat di hindari. Hampir sumua di setiap penyelenggaraan pemilu Pegawai Negeri Sipil melakukan pelanggaran. Dilihat dari paling besar pengaruhnya yaitu hubungan internal terhadap pasangan calon menjadi alasan Pegawai Negeri Sipil ini menyimpang terhadap Undang-Undang yang ada. Saran dari penulisan skripsi ini yang pertama 
Netralitas di artikan bahwa Pegawai Negeri Sipil mempunyai hak suara untuk memilih hanya saja tidak boleh mengikuti kampanye yang di lakukan pasangan calon. Dengan demikian ke netralitasan Pegawai Negeri ini sangat di mungkinkan pelaksanaan pemilu dapat semakin baik.

2. Pemerintah harus benar-benar mempersiapkan perangkat peraturan untuk pemilu presiden dan legislative ini agar tujuan positif pemilu serentak bisa terwujud yaitu sistem presidensial yang kuat untuk menjalankan roda pemerintahan secara efisien. Penyesuaian sistem pemilu serentak dengan sistem lain sangat diperlukan agar kelemahan pada pemilu serentak dapat di perbaiki dan menjadi bahan evaluasi di pemlu lima tahun kedepan, misalnya bagaimana mencari solusi bagaimana agar angka pelanggaran pemilu bisa berkurang, memberikan edukasi terhadap masyarakat terkait larangan apa saja yang tidak diperbolehkan dilakukan bagi peserta maupun penyelengara dalam pelakasanaan tahapan pemilihan umum berlangsung.

\section{DAFTAR PUSTAKA}

\section{A. BUKU/JURNAL}

Jimly Asshiddiqie, Pengantar Ilmu Hukum Tata Negara.Jakarta: Rajawali Pers,2019

Bawaslu Kabupaten Indramayu "Dibalik Pintu Pengawasan Bawaslu Kabupaten Indramayu, pada Pemilu serentak 2019”, Indramayu 2019.

Hartini, Sri "Penegakan Hukum Netralitas Pegawai Negeri Sipil (PNS)" Jurnal Dinamika Hukum Vol. 9. No. 3, September 2009

Marbun, S.F.1998. Reformasi Hukum Tata Negara”, Netralitas Pegawai Negeri dalam Kehidupan Politik di Indonesia. Yogyakarta: Fakultas Hukum Universitas Islam Indonesia

Kadarsih, Setiajeng, dan Sri Hartini, Makalah Netralitas Pegawai Negeri, Yogjakarta, 2005.

\section{B. Peraturan Perundang-Undangan:}

- Undang-undang Nonor 7 Tahun 2017 tentang Pemilihan Umum

- Undang-undang Nomr 5 Tahun 2017 tentang Aparatur Sipil Negara (ASN) 


\section{Sumber Lain}

Data Daring Bawaslu RI https://www.bawaslu.go.id/id/berita/bawaslu-tangani-ribuanpelanggaran-netralitas-asn-saat-pemilu-2019) diakses pada tanggal 14 Februari 2020 Pukul 09:15 WIB 